\title{
Analisis Perbandingan Teknik Video Codec H.264/AVC, H.265/HEVC, VP9 dan AV1
}

\author{
Ayu Shafira Tubagus ${ }^{* 1}$, Rizal Saepul Mahdi ${ }^{2}$, Adhi Rizal ${ }^{3}$, Aries Suharso ${ }^{4}$ \\ 1,2,3,4 Proram Studi Teknik Informatika, Universitas Singaperbangsa Karawang \\ email: ayu.shafira17064@student.unsika.ac.id*1, 1610631170194@ student.unsika.ac.id ${ }^{2}$, \\ adhi.rizal@staff.unsika.ac.id ${ }^{3}$, aries.suharso@staff.unsika.ac.id ${ }^{4}$
}

(Received: 29 Juli 2021/ Accepted: 7 Agustus 2021/ Published Online: 20 Desember 2021)

\begin{abstract}
Abstrak
Aplikasi video terus berkembang di internet dan dapat diakses dengan perangkat elektronik, hal ini menyebabkan pertumbuhan konsumsi konten video dengan resolusi dan kualitas tinggi sehingga menimbulkan tantangan berat pada infrastruktur pengiriman yang memiliki kebutuhan lebih kuat untuk teknologi kompresi video. Penelitian ini bertujuan untuk mendapatkan informasi perubahan kualitas pada codec terbaru yaitu AV1 dengan codec pendahulunya. Adapun perbandingan dilakukan secara eksperimental pada dua resolusi video (1080p dan 720p) dengan cara pengambilan sampel frame video yang diberikan nilai CRF/CQP dengan preset encoder berbeda dan pengujian beberapa tes parameter seperti durasi pengkodean, rasio kompresi, bitrate, Mean Square Error (MSE) dan Peak Signal to Noise Ratio (PSNR). Hasil penelitian menunjukkan bahwa codec AV1 sangat baik dalam kualitas dan ukuran file, akan tetapi buruk dalam kecepatan kompresi. Namun, rasio kompresi codec H.265/HEVC lebih baik dibanding ketiga codec lainnya. Oleh karena itu, sebagai bahan rekomendasi untuk mendapatkan video hasil kompresi yang baik dengan ukuran file kecil dan waktu kompresi yang cepat yaitu menggunakan codec H.265/HEVC.
\end{abstract}

Kata kunci: Codec, Kompresi Video, Mean Square Error, Peak Signal to Noise Ratio,Video Digital

\section{Abstract}

Video applications consume more energy on the Internet and can be accessed by electronic devices, due to an increase in the consumption of high-resolution and high-quality video content, presenting serious issues to delivery infrastructure that needs higher video compression technologies. The focus of this paper is to evaluate the quality of the most current codec, AVI, to its predecessor codec. The comparison was made experimentally at two video resolutions (1080p and 720p) by sampling video frames with various CRF/CQP values and testing several parameters analyses such as encoding duration, compression ratio, bit rate, Mean Square Error (MSE), and Peak Signal to Noise Ratio (PSNR). The AVI codec is very great in terms of quality and file size, even though it is slower in terms of compression speed. The H.265/HEVC codec, on the other side, beats the other codec in terms of compression ratio. In conclusion, the H.265/HEVC codec is suggested as a material for obtaining a well compressed video with small file size and a short time.

Keywords: Codec, Video Compression, Mean Square Error, Peak Signal to Noise Ratio, Digital Video

\section{PENDAHULUAN}

Semakin pesatnya perkembangan teknologi internet, manusia tidak terlepas dari kebutuhan untuk mengakses multimedia digital seperti gambar, audio dan video. Meski demikian, video merupakan salah satu jenis multimedia yang paling diminati masyarakat dalam beberapa tahun terakhir (Chen et al., 2019). Dilansir dari (Cisco, 2017), saat ini sekitar 75\% transmisi data melalui jaringan di seluruh dunia adalah konten video. Jumlah ini semakin bertambah dan diprediksi akan meningkat lebih signifikan dari tahun ke tahun. Untuk memenuhi kebutuhan pengguna akan konsumsi konten dengan resolusi dan kualitas yang tinggi. Hal tersebut dapat menimbulkan tantangan berat pada infrastruktur pengiriman dan 
karenanya menciptakan kebutuhan yang lebih kuat untuk teknologi kompresi video dengan efisiensi tinggi (Idris et al., 2019).

Berdasarkan studi beberapa tahun lalu hingga studi saat ini, penilaian kualitas audio dan video masih menjadi permasalahan yang menarik dan terus berkembang (Ram \& Panwar, 2017). Adanya tren tersebut, teknik encoding video menjadi topik yang paling sering dibahas dalam komunitas riset dan pakar penyiaran. Hal ini terjadi karena adanya evolusi atau perkembangan standar video dalam teori harus sejalan dan dapat diterapkan dalam teknologi tertentu. Terutama perusahaan penyiaran digital sudah mulai menyajikan konten UHD di saluran TV digital (Deep \& Elarabi, 2017).

Permasalahan ini memicu peningkatan kebutuhan akan kompresi video. Oleh karena itu, dalam bidang pengkodean video kebutuhan paling kritis adalah untuk meningkatkan efisiensi dengan biaya yang lebih rendah (Akyazi \& Ebrahimi, 2018). Saat ini, beberapa teknik atau metode yang terkait dengan pengkodean video telah muncul. Beberapa paling dikenal dan populer digunakan adalah H.261, MPEG-2, MPEG-4, H.264 / AVC, H.265 / HEVC, VP9, AV1, dan sebagainya (Akyazi \& Ebrahimi, 2018; Chen et al., 2019; Rabie \& Baziyad, 2020; Zhang \& Mao, 2019).

Beberapa penelitian juga telah dilakukan untuk membandingkan kualitas dan kinerja teknik pengkodean video. Penelitian yang dilakukan oleh (Rizal et al., 2020) bertujuan untuk membandingkan teknik H.264 dengan H.265 untuk mengetahui performansi. Hasil penelitian ini menunjukkan bahwa H.264 lebih cepat dari segi waktu yang dibutuhkan untuk melakukan proses encoding. Selain itu kualitas keluaran video yang dihasilkan oleh H.264 juga lebih baik, namun tidak signifikan hanya sedikit berbeda dengan H.265 dan tidak bisa dilihat secara langsung. Selain itu, rasio kompresi dan bitrate H.265 lebih baik dari pendahulunya dengan selisih 38,5\% dan 52,7\%. Kemudian penelitian oleh Saepul, (2020) bertujuan untuk membuat penilaian subjektif dan objektif dari tiga teknik kompresi video, H.264, H.265 dan VP9. Penelitian ini menghasilkan bahwa H.264 lebih cepat dalam hal kecepatan kompresi dengan rata-rata waktu kompresi sekitar 14 menit. Sedangkan H.265 dan VP9 memiliki rata-rata waktu kompresi sekitar 38 menit dan 60 menit. Untuk ukuran file kompresi, H.265 lebih baik daripada H.264 dan VP9 dengan rata-rata ukuran mencapai 83,49 MB yang jauh lebih kecil dibanding H.265 dengan rata-rata ukuran 93,32 MB dan VP9 dengan rata-rata ukuran file sebesar 179,26 MB. Untuk rasio kompresi, H.265 lebih baik daripada H.264 dan VP9 dengan rata-rata rasio kompresi sebesar 22,47\% yang jauh lebih tinggi dibanding H.265 dengan rata-rata rasio kompresi sebesar 19,32\% dan VP9 dengan rata-rata rasio kompresi sebesar 6,27\%. Sedangkan untuk kualitas citra dan bitrate, VP9 lebih baik daripada H.264 dan H.265 dengan catatan ratarata nilai MSE sebesar 1,99, rata-rata nilai PSNR sebesar 45,46 dB, dan jumlah bitrate sebesar $5,38 \mathrm{Mb} / \mathrm{s}$.

Penelitian selanjutnya dilakukan oleh (Layek et al., 2017) bertujuan untuk memastikan analisis yang adil dengan penggunaan parameter berbeda. Dengan parameter default, untuk bitrate video yang sama, AV1 memperoleh kualitas yang lebih baik dibandingkan dengan pengkodean lainnya. Namun, ketika menggunakan "Plasebo" terlihat bahwa waktu paling lambat terdapat pada codec H.264 dan H.265, AV1 berjalan sedikit di belakang H.265. Diantara dua lainnya, VP9 selalu mengungguli H.264. Untuk semua skema, dengan meningkatnya kualitas, waktu pengkodean juga meningkat.

Ada banyak teknik pengkodean video yang tersedia, tetapi H.264 / AVC (Wiegand et al., 2003) dan H.265 / HEVC (Sullivan et al., 2012) adalah dua standar pengkodean video terbaru yang dikembangkan oleh Video Coding Expert Group (VCEG) dan ISO / IEC Moving Picture Expert Group (MPEG). H.264 dianggap sebagai standar yang matang (Layek et al., 2017) dan banyak digunakan untuk berbagai aplikasi baik real-time maupun non real-time. Sedangkan H.265 merupakan evolusi dari pendahulunya dengan target penghematan bitrate 50\% tetapi memiliki kualitas encoding yang serupa (Akyazi \& Ebrahimi, 2018). VP9 adalah penerus VP8, 
format kompresi video terbuka yang mulai dikembangkan pada akhir tahun 2011 oleh Google. Tujuan utamanya adalah menyediakan solusi bebas royalti untuk video berbasis internet (Idris et al., 2019). AV1 merupakan perkembangan dari VP9, yang memperkenalkan skema partisi berbentuk T yang diwarisi dari VP10 untuk unit pengkodean. AV1 memprediksi koefisien chroma dari koefisien luma (Akyazi \& Ebrahimi, 2018).

Meskipun banyak penelitian berfokus pada penilaian kualitas objektif yang ditentukan oleh nilai CRF atau CQP dan preset encoder. Dengan jumlah parameter yang dapat disesuaikan dan dikonfigurasi (Layek et al., 2017b; Rizal et al., 2020). Pemilihan preset encoder tertentu sebenarnya untuk menyesuaikan beberapa parameter internal, seperti jumlah B-Frame, rekursi, ukuran Coding Tree Unit (CTU), lookahead dan sebagainya. Walaupun pemilihan preset yang lebih lambat dengan menggunakan bitrate tetap menghasilkan kualitas video yang lebih baik dibandingkan dengan penggunaan preset yang lebih cepat, kondisi ini tidak selalu terpenuhi (Idris et al., 2019). Berdasarkan hal ini, jika kita mengetahui performa untuk setiap pengaturan nilai CRF dan preset, kita dapat memilih aplikasi tertentu secara efektif. Oleh karena itu, penelitian ini bertujuan untuk mendapatkan informasi perubahan kualitas codec video terbaru dengan codec pendahulunya menggunakan penilaian objektif dan penilaian secara komprehensif perbandingan pada dua resolusi video (1080p dan 720p) yang diberikan nilai $\mathrm{CRF}$ atau CQP dengan preset encoder yang berbeda dan penggunaan beberapa tes parameter seperti durasi pengkodean, rasio kompresi, bitrate, Mean Square Error (MSE) dan Peak Signal to Noise Ratio (PSNR).

\section{METODE}

Bagian ini menjelaskan konfigurasi sumber video yang dipilih, lingkungan pengujian mencakup perangkat keras dan lunak yang digunakan, pemilihan nilai CRF atau CQP dan preset encoder, parameter pengujian kinerja, skenario penilaian. Untuk mendapatkan hasil analisis yang komprehensif, penelitian ini menggunakan tiga video mentah dengan resolusi 1080p yang akan dikodekan menggunakan keempat teknik yang dibandingkan. Video ini terdiri dari kamera video (Boyce Avenue), animasi 2D (Chika Dance), dan animasi 3D (Beast Fiction) yang namapak pada tabel 1.

Tabel 1. Video Sumber yang Dipilih

\begin{tabular}{ccccccc}
\hline Nama file & Format & Resolusi & Durasi (s) & FPS & $\begin{array}{c}\text { Bitrate } \\
(\mathbf{M b} / \mathbf{s})\end{array}$ & $\begin{array}{c}\text { Ukuran } \\
(\mathbf{M B})\end{array}$ \\
\hline $\begin{array}{c}\text { BEAST } \\
\text { FICTION }\end{array}$ & MPEG-2 & $1920 \times 1080$ & 311 & 29,97 & 1,791 & 83,5 \\
$\begin{array}{c}\text { 1080p.mpg } \\
\text { Chika } \\
\text { Dance.mpg } \\
\text { Boyce }\end{array}$ & MPEG-2 & $1920 \times 1080$ & 101 & 29,97 & 9,128 & 27,6 \\
Avenue.mpg & MPEG-2 & $1920 \times 1080$ & 209 & 29,97 & 10,1 & 54,0 \\
\hline
\end{tabular}

\section{Lingkungan Eksperimen}

Penelitian ini menggunakan tool HandBrake dan NotEnoughAV1Encodes. Dengan Spesifikasi komputer penelitian sebagai berikut: Sistem Operasi Windows 10 Home Single Language 64-bit, Prosesor CPU Intel @ Core TM i3-6006U CPU @2.00GHz, RAM 12 GB, VGA NVIDIA GeForce 920mx. CRF/CQP dan preset encoder diatur dalam perangkat lunak HandBrake dan Not Enough AV1Encodes untuk menghasilkan peningkatan yang signifikan pada ukuran video keluaran ataupun sebaliknya. Konfigurasi nilai CRF/CQP standar yang wajar adalah antara 18 dan 28. Sedangkan khusus untuk konfigurasi H.264 / AVC dan H.265 / 
HEVC masing-masing adalah 23 dan 28. Adanya hal tersebut, penelitian ini memilih nilai CRF/CQP yang mendekati kriteria tersebut, 18, 23, 28, dan 33 (Robitza, 2017).

Layek et al., (2017), menyatakan bahwa preset default adalah medium, sedangkan paling lambat yaitu placebo yang membutuhkan waktu encoding yang sangat lama dan tidak sebanding dengan kualitas yang dihasilkan. Maka dari itu, penelitian ini menggunakan preset kecepatan tertinggi (ultrafast), sedang (medium), dan lambat (slow).

Untuk mengetahui performansi keempat teknik tersebut, penelitian ini menggunakan beberapa parameter pengujian, seperti: durasi encoding, rasio kompresi, bitrate, MSE dan PSNR. Durasi encoding menunjukkan berapa lama waktu kompresi yang dibutuhkan untuk proses encoding. Rasio kompresi adalah rasio-persentase antara ukuran video sebelum kompresi dan ukuran video setelah kompresi. Bitrate berkaitan dengan kualitas gambar yang dihasilkan. MSE adalah penduga metrik pengukuran kualitas citra membandingkan dua citra yang didefinisikan dalam persamaan 1.

$$
M S E=\frac{1}{M N} \sum_{x=1}^{M} \sum_{y=1}^{N}\left[I_{(x, y)}-I^{\prime}(x, y)\right]^{2}
$$

Sedangkan PSNR membandingkan sinyal dari setiap bingkai video dalam sumber video dengan setiap bingkai keluaran video dan mengukur perbedaan diantara keduanya (Sara et al., 2019). Rasio dua video atau gambar dihitung dalam decibel. PSNR didefinisikan dalam persamaan 2.

$$
P S N R=20 \log _{10}\left[\frac{255}{\sqrt{M S E}}\right]
$$

Penelitian ini menggunakan Matlab R2017a untuk menganalisis parameter MSE dan PSNR. Sebelum pengujian dilakukan, perlu mengekstrak frame dari sumber dan keluaran video. Kemudian diambil sampel frame yang sama untuk dianalisis. Proses encoding pada H.264 / AVC dan H.265 / HEVC adalah membagi citra menjadi macroblock berukuran 8x8, yang terdiri dari komponen $\mathrm{Y}$ (luminance), $\mathrm{Cb}$ dan $\mathrm{Cr}$ (color / chrominance). Ukuran maksimum macroblock H.264 / AVC dan H.265 / HEVC adalah 16x16, pada codec VP9 adalah 64x64, sedangkan pada codec AV1 adalah 128x128. Oleh karena itu, seperti pada (Ostermann et al., 2004), ukuran macroblock yang digunakan untuk proses penelitian adalah ukuran minimum macroblock, yaitu 8x8.

\section{HASIL DAN PEMBAHASAN Hasil}

Informasi mengenai waktu yang dibutuhkan untuk encode dari setiap skenario pengujian dapat dilihat pada gambar 1. Terlihat bahwa durasi encoding yang paling lambat (sekitar 5 jam 13 menit) adalah proses encoding AV1 dengan resolusi 1080p, preset slow dan CQP 18. Sedangkan durasi proses encoding tercepat (sekitar 1 menit 20 detik) adalah proses encoding H.264/AVC dengan resolusi 720p, preset ultrafast dan CRF 18. Oleh karena itu, teknik H.264 secara keseluruhan memiliki durasi encoding yang lebih cepat dibandingkan dengan AV1 dengan selisih yang cukup besar yaitu hampir 311 menit. Dapat diketahui bahwa waktu yang dibutuhkan untuk melakukan suatu proses encoding dipengaruhi oleh beberapa kondisi ataupun konfigurasi. Semakin rendah resolusinya, tetapi dengan preset tercepat dan nilai CRF/CQP yang lebih besar, semakin cepat proses encoding. Berdasarkan hal tersebut, jika kita menginginkan waktu proses encoding yang lebih cepat, kita dapat mempertimbangkan untuk memilih keluaran video dengan resolusi keluaran rendah, tetapi dengan preset tercepat dan nilai CRF/CQP tertinggi. 

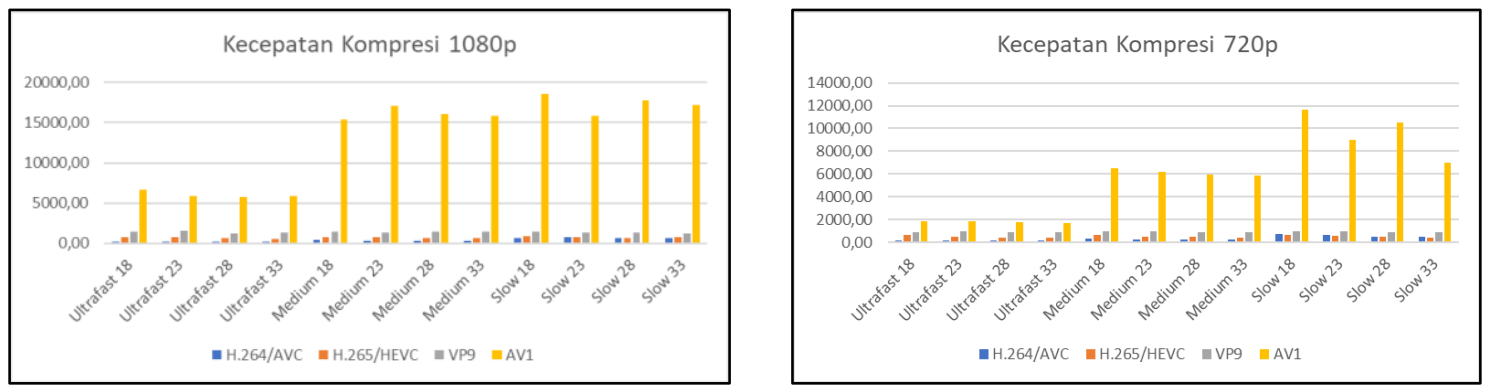

Gambar 1. Durasi pengkodean H.264, H.265, VP9 dan AV1

Pada gambar 2, dapat dilihat bahwa rasio kompresi terbesar dimiliki oleh codec H.265 / HEVC dengan nilai rasio sebesar 54,07\% dengan resolusi 720p, preset medium, dan nilai CRF 33. Sedangkan nilai rasio kompresi terkecil dimiliki oleh codec AV1 dengan nilai rasio kompresi sebesar $0,93 \%$ dengan resolusi $1080 \mathrm{p}$, preset slow dan nilai CQP 28. Hal ini menunjukkan bahwa semakin kecil resolusi video, dengan konfigurasi preset tinggi dan nilai $\mathrm{CRF} / \mathrm{CQP}$ yang tinggi akan menghasilkan nilai rasio kompresi yang besar.
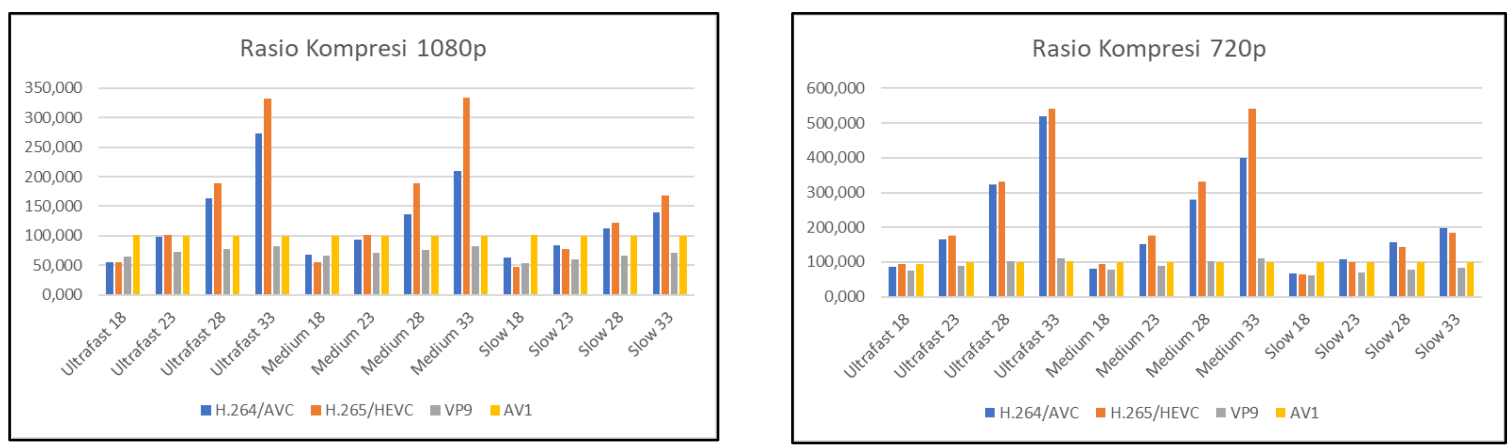

Gambar 2. Rasio Kompresi H.264, H.265, VP9 dan AV1

Hasil bitrate pada gambar 3 mengalami penurunan berdasarkan nilai CRF/CQP yang semakin tinggi pada masing-masing konfigurasi preset. Jumlah bitrate tertinggi terdapat pada codec H.264/AVC dengan nilai 8,53 Mbps (1080p, preset medium, CQP 18). Sedangkan jumlah bitrate terendah dimiliki codec AV1 dengan jumlah bitrate 0,4 Mbps (720p, preset ultrafast, CRF 28). Pada Gambar 3 juga dapat dilihat bahwa semakin kecil resolusi video dengan preset cepat dan nilai CRF/CQP tinggi akan menghasilkan jumlah bitrate yang semakin sedikit. Begitu juga sebaliknya, semakin besar resolusi video dengan preset lambat dan nilai $\mathrm{CRF} / \mathrm{CQP}$ rendah maka akan menghasilkan jumlah bitrate yang besar.
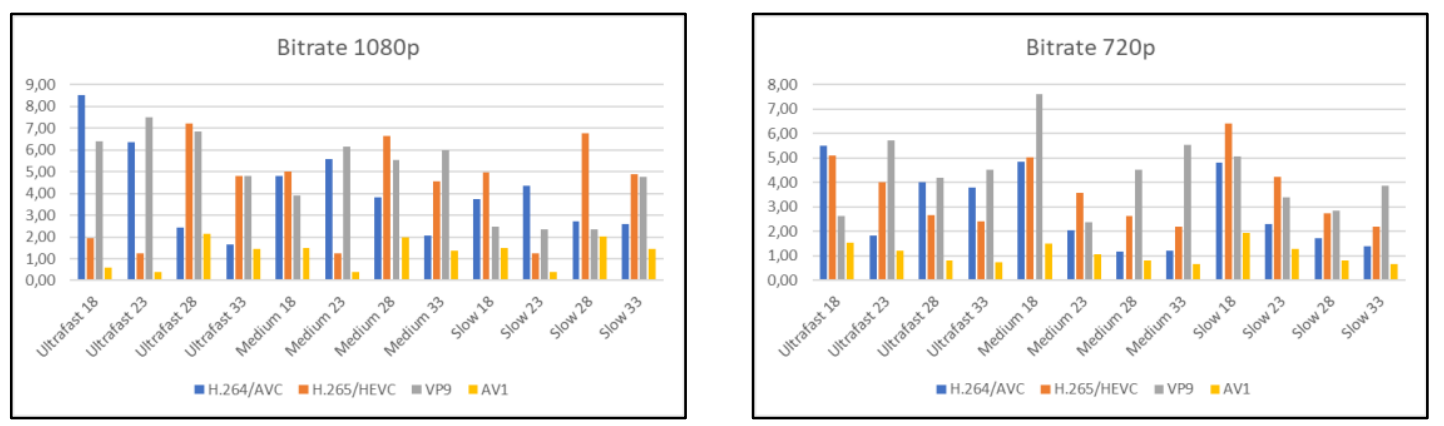

Gambar 3. Bitrate H.264, H.265, VP9 dan AV1

Gambar 4 adalah hasil nilai MSE pada setiap codec mengalami peningkatan secara konsisten berdasarkan nilai CRF/CQP yang semakin besar. Semakin kecil nilai MSE maka 
semakin baik citra kompresi video yang dihasilkan. Nilai MSE terbaik pada codec AV1 dengan nilai 0,125 (720p, preset slow, CQP 18) dan nilai MSE terburuk terdapat pada codec H.264/AVC dengan nilai 3,130 (1080p, preset ultrafast, CRF 33). Selanjutnya pada gambar 5, dapat dilihat bahwa nilai PSNR pada setiap codec mengalami penurunan nilai secara konsisten berdasarkan nilai CRF dan CQP yang semakin besar. Semakin besar nilai PSNR maka semakin baik citra kompresi video yang dihasilkan. Dari grafik tersebut dapat disimpulkan bahwa nilai PSNR terbaik terdapat pada codec AV1 dengan nilai 43,059 dB (1080p, preset ultrafast, CQP 23). Sedangkan nilai PSNR terburuk terdapat pada codec H.264/AVC dengan nilai 36,020 dB (1080p, preset ultrafast, CRF 33). Adapun rata-rata nilai PSNR untuk masing-masing codec yaitu 38,037 dB untuk codec H.264/AVC, 38,360 dB untuk codec H.265/AVC, 40,323 dB untuk codec VP9 dan 42,743 dB untuk codec AV1.
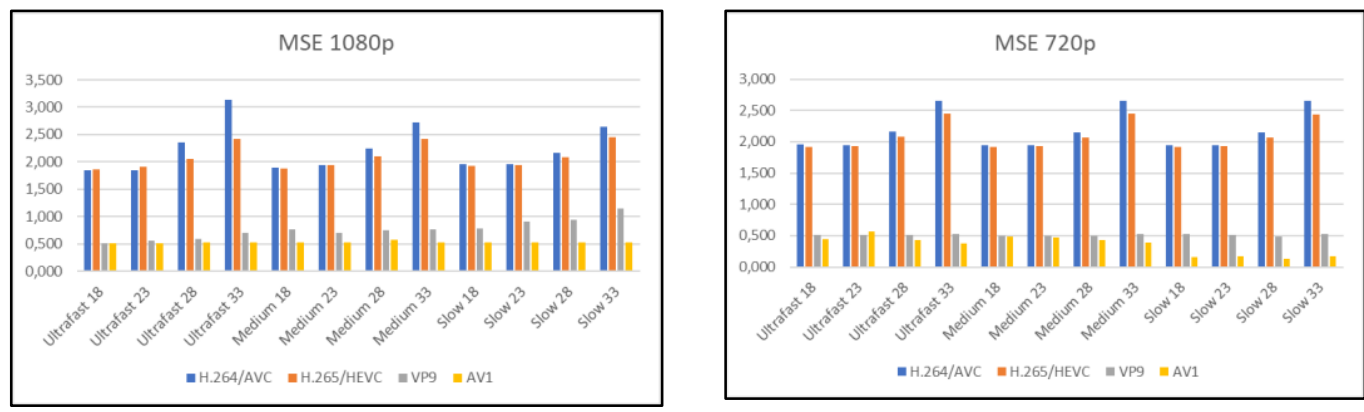

Gambar 4. Nilai MSE H.264, H.265, VP9 dan AV1
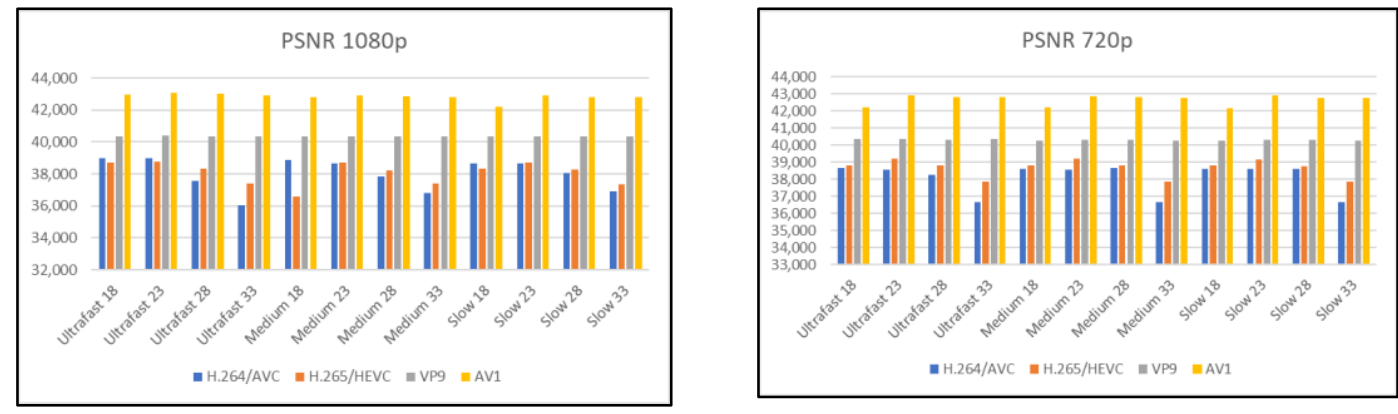

Gambar 5. Nilai PSNR H.264, H.265, CP9 dan AV1

\section{Pembahasan}

Berdasarkan tabel 3, dapat dilihat masing-masing nilai pada codec H.264/AVC, H.265/HEVC, VP9 dan AV1 berdasarkan parameter-parameter yang diuji mulai dari kecepatan kompresi, ukuran file kompresi, rasio kompresi, bitrate, dan nilai MSE PSNR. Pada gambar 6, dapat dilihat bahwa ukuran file kompresi dan bitrate kompresi codec AV1 lebih baik daripada codec H.265/HEVC. AV1 memiliki ukuran file lebih kecil dikarenakan memiliki teknik pengkodean Motion Vectors yang sedemikian rupa sehingga tidak terlihat kerugiannya oleh mata manusia.

Ukuran file lebih kecil kedua yaitu H.265/HEVC dikarenakan codec ini dapat mengkompres bitrate dua kali lebih baik sehingga ukuran video yang dihasilkan lebih kecil tetapi tidak mempengaruhi juga pada kualitas video nya. Untuk rasio kompresi sendiri, codec VP9 memiliki jumlah rasio kompresi yang lebih kecil daripada codec AV1, H.264/AVC dan H.265/HEVC. Semakin besar ukuran file sebuah video, maka semakin besar juga jumlah bitrate nya. Untuk nilai MSE, codec AV1 memiliki nilai MSE yang lebih kecil daripada codec H.264/AVC, H.265/HEVC dan VP9. Sedangkan untuk nilai PSNR, berbanding terbalik dengan nilai MSE. Semakin kecil nilai MSE maka semakin besar nilai PSNR yang diperoleh. Oleh karena itu, codec AV1 memiliki nilai PSNR yang lebih besar daripada codec H.264/AVC, H.265/HEVC dan VP9. Nilai MSE dan PSNR inilah yang mempengaruhi kualitas citra sebuah 
video. Semakin kecil nilai MSE yang diperoleh, maka semakin baik citra kompresi video yang dihasilkan dan semakin besar nilai PSNR yang diperoleh, maka semakin baik citra kompresi video yang dihasilkan.

Tabel 3. Hasil Analisis Keseluruhan

\begin{tabular}{ccccccc}
\hline & \multicolumn{2}{c}{ Kecepatan } & \multicolumn{2}{c}{ Ukuran File } & \multicolumn{2}{c}{ Rasio Kompresi } \\
Codec & \multicolumn{2}{c}{ Kompresi (s) } & \multicolumn{2}{c}{ Kompresi (MB) } & \multicolumn{2}{c}{$(\boldsymbol{\%})$} \\
& $\mathbf{1 0 8 0 p}$ & $\mathbf{7 2 0} \mathbf{p}$ & $\mathbf{1 0 8 0 p}$ & $\mathbf{7 2 0 p}$ & $\mathbf{1 0 8 0}$ & $\mathbf{7 2 0 p}$ \\
\hline H.264/AVC & 395,22 & 322 & 61,7 & 41,9 & 120,69 & 172,15 \\
H.265/HEVC & 725,19 & 496 & 49,7 & 29,9 & 143,97 & 182,67 \\
VP9 & 1376,31 & 914 & 84,1 & 66,0 & 17,58 & 54,67 \\
AV1 & 13174,78 & 5811,00 & 15,1 & 9,0 & 92,07 & 92,19 \\
\hline
\end{tabular}

Tabel 4. Hasil Analisis Keseluruhan (Lanjutan)

\begin{tabular}{ccccccc}
\hline \multirow{2}{*}{ Codec } & \multicolumn{2}{c}{ Bitrate $(\boldsymbol{M b} / \boldsymbol{s})$} & \multicolumn{2}{c}{$\boldsymbol{M S E}$} & \multicolumn{2}{c}{ PSNR (dB) } \\
& 1080p & $\mathbf{7 2 0 p}$ & $\mathbf{1 0 8 0 p}$ & $\mathbf{7 2 0 p}$ & $\mathbf{1 0 8 0 p}$ & $\mathbf{7 2 0 p}$ \\
\hline H.264/AVC & 4,06 & 2,88 & 2,22 & 2,17 & 37,99 & 38,08 \\
H.265/HEVC & 4,20 & 3,60 & 2,07 & 2,09 & 38,07 & 38,65 \\
VP9 & 4,93 & 4,35 & 0,75 & 0,51 & 40,35 & 40,29 \\
AV1 & 1,26 & 1,08 & 0,52 & 0,35 & 42,83 & 42,65 \\
\hline
\end{tabular}
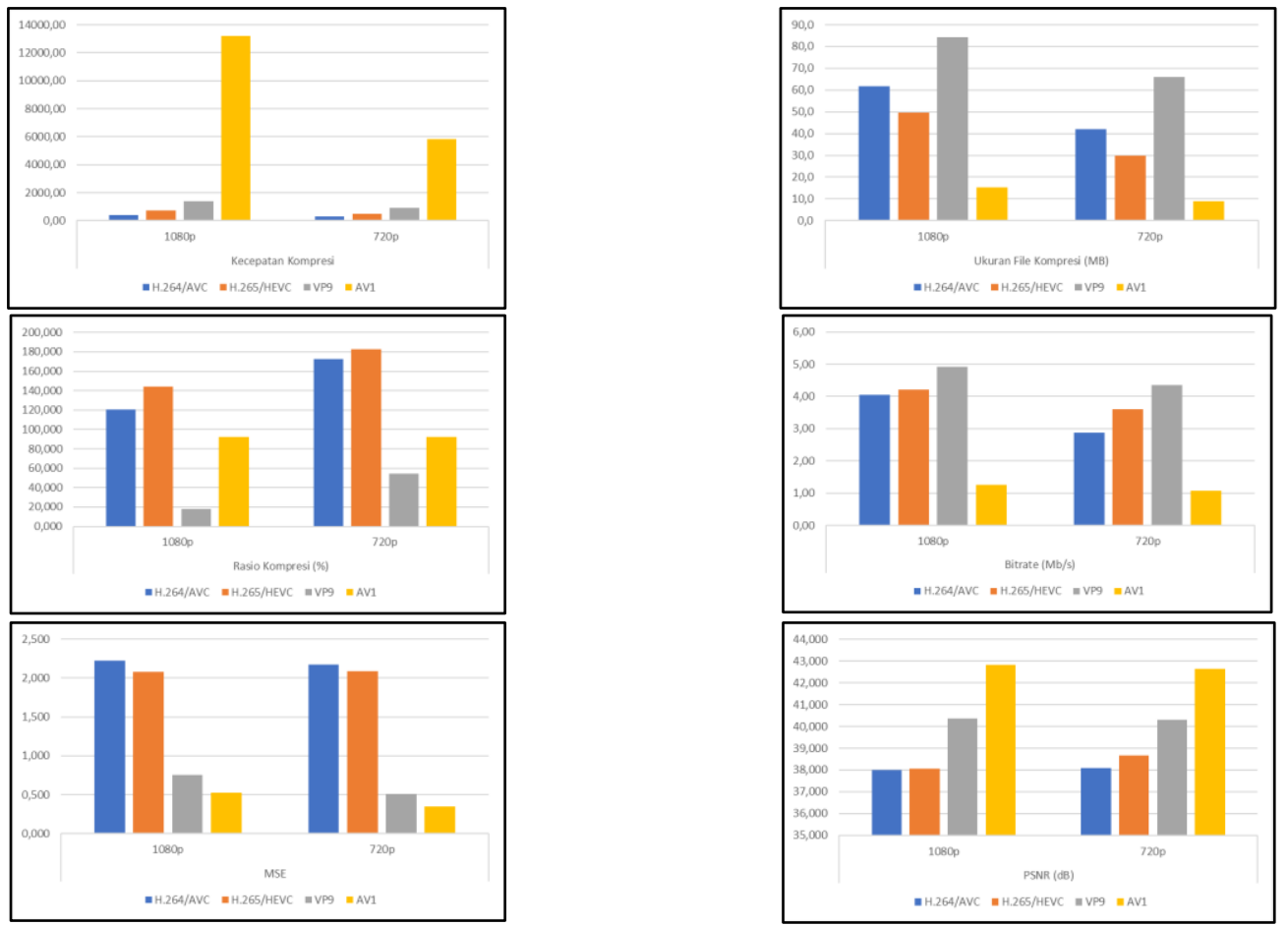

Gambar 6. Hasil Analisis Secara Keseluruhan

Sementara itu, penelitian sebelumnya dengan kasus penambahan codec VP9 sebagai perbandingan yang dilakukan oleh (Harto et al., 2020), menyimpulkan bahwa VP9 lebih unggul dalam hal kualitas akan tetapi buruk dalam hal ukuran dan kecepatan kompresi. Untuk codec H.264/AVC unggul dalam hal kecepatan kompresi, tidak terlalu besar dalam hal ukuran file, tetapi buruk dalam hal kualitas video. Sedangkan untuk codec H.264/HEVC, memiliki peringkat yang tidak terlalu buruk. Dalam hal ukuran file H.265/HEVC sangat unggul 
dibanding codec H.264/AVC dan VP9. Untuk itu perlu dilakukan penelitian dengan codec terbaru sehingga mendapatkan hasil terbaik dengan perbandingan parameter yang tepat.

\section{SIMPULAN}

Berdasarkan hasil penelitian, dapat disimpulkan bahwa setiap teknik pengkodean video memiliki kelebihan dan kekurangan. Penggunaan beberapa parameter pengujian sangat berpengaruh terhadap hasil analisis perbandingan kualitas pada codec H.264/AVC, H.265/HEVC, VP dan AV1 sehingga yang optimal. Dilihat dari hasil analisis keseluruhan yang dihasilkan bahwa codec AV1 lebih unggul dalam hal kualitas akan tetapi buruk dalam hal kecepatan kompresi.

\section{REFERENSI}

Akyazi, P., \& Ebrahimi, T. (2018). Comparison Of Compression Efficiency Between HEVC/H. 265, VP9 and AV1 Based On Subjective Quality Assessments. 2018 Tenth International Conference on Quality of Multimedia Experience (QoMEX), 1-6.

Chen, Z., He, T., Jin, X., \& Wu, F. (2019). Learning for Video Compression. IEEE Transactions on Circuits and Systems for Video Technology, 30(2), 1-11. https://doi.org/10.1109/TCSVT.2019.2892608

Deep, V., \& Elarabi, T. (2017). HEVC/H. 265 vs. VP9 state-of-the-art video coding comparison for HD and UHD applications. 2017 IEEE 30th Canadian Conference on Electrical and Computer Engineering (CCECE), 1-4.

Harto, V., Primananda, R., \& Suharsono, A. (2020). Analisis Performansi H.264 dan H.265 pada Video Streaming dari Segi Quality Of Service. Jurnal Pengembangan Teknologi Informasi Dan Ilmu Komputer, 1(10), 1172-1181. https://j-ptiik.ub.ac.id/index.php/jptiik/article/view/358

Idris, M. H., Tri hanHanuranto, A., \& Sanjoyo, D. D. (2019). Analisis Performansi Video Kompresi H. 265 (HEVC) Dan VP9 Pada Layanan Video Streaming Internet Protocol Television (IPTV) Dari Segi Quality Of Service (QOS). EProceedings of Engineering, $6(2), 1-8$.

Layek, M. A., Thai, N. Q., Hossain, M. A., Thu, N. T., Talukder, A., Chung, T., \& Huh, E.-N. (2017a). Analysis Of The Effects Of Timing Presets On The Performance of H. 264/AVC and H. 265/HEVC Video Encoders. 한국통신학회 학술대회논문집, 442-443.

Layek, M. A., Thai, N. Q., Hossain, M. A., Thu, N. T., Talukder, A., Chung, T., \& Huh, E.-N. (2017b). Performance Analysis of H. 264, H. 265, VP9 and AV1 Video Encoders. 2017 19th Asia-Pacific Network Operations and Management Symposium (APNOMS), 322325. https://doi.org/10.1109/APNOMS.2017.8094162

Ostermann, J., Bormans, J., List, P., Marpe, D., Narroschke, M., Pereira, F., Stockhammer, T., \& Wedi, T. (2004). Video coding with H. 264/AVC: tools, performance, and complexity. IEEE Circuits and Systems Magazine, 4(1), 7-28.

Rabie, T., \& Baziyad, M. (2020). PixoComp: a novel video compression scheme utilizing temporal pixograms. Multimedia Tools and Applications, 79(19), 13179-13196.

Ram, C., \& Panwar, S. (2017). Performance comparison of high efficiency video coding (HEVC) with H. 264 AVC. International Conference on Signal-Image Technology \& Internet-Based Systems (SITIS), 303-310. India: IEEE. https://doi.org/10.1109/SITIS.2017.58

Rizal, A., Suharso, A., Abujabbar, P., \& Munir, M. (2020). Objective Quality Assessment of Multi-Resolution Video based on H.264/AVC and H.265/HEVC Encoding. Proceedings of the 7th Mathematics, Science, and Computer Science Education International Seminar, MSCEIS 2019. Bandung, Indoensia: EAI. https://doi.org/http://dx.doi.org/10.4108/eai.1210-2019.2296550 
Robitza, W. (2017). CRF Guide (Faktor Tingkat Konstan dalam x264 dan x265). Https://Slhck.Info. https://slhck.info/video/2017/02/24/crf-guide.html

Sara, U., Akter, M., \& Uddin, M. S. (2019). Image quality assessment through FSIM, SSIM, MSE and PSNR - a comparative study. Journal of Computer and Communications, 7(3), 8-18.

Sullivan, G. J., Ohm, J.-R., Han, W.-J., \& Wiegand, T. (2012). Overview Of The High Efficiency Video Coding (HEVC) Standard. IEEE Transactions on Circuits and Systems for Video Technology, 22(12), 1649-1668.

Wiegand, T., Sullivan, G. J., Bjontegaard, G., \& Luthra, A. (2003). Overview Of The H. 264/AVC Video Coding Standard. IEEE Transactions on Circuits and Systems for Video Technology, 13(7), 560-576.

Zhang, T., \& Mao, S. (2019). An overview of emerging video coding standards. GetMobile: Mobile Computing and Communications, 22(4), 13-20. 